\title{
Exosomes and Metabolic Diseases
}

\author{
Julieta Díaz-Juárez ${ }^{1}$ and Jorge Suarez ${ }^{2^{*}}$ \\ ${ }^{1}$ Department of Pharmacology, Instituto Nacional de Cardiología Ignacio Chávez, Ciudad de México, México \\ ${ }^{2}$ Department of Medicine, University of California, San Diego, USA
}

"Corresponding author: Jorge Suarez, Department of Medicine, University of California, San Diego, USA, Tel: (858) 534-9931; Fax: (858) 534-9932; E-mail: jsuarez@ucsd.edu

Received date: August 10, 2017; Accepted date: August 11, 2017; Published date: August 18, 2017

Copyright: @ 2017 Díaz-Juárez J, et al. This is an open-access article distributed under the terms of the creative commons attribution license, which permits unrestricted use, distribution, and reproduction in any medium, provided the original author and source are credited.

\section{Editorial}

Metabolic syndrome (MetS) is an arrangement of cardiovascular and metabolic risk factors that dramatically increase cardiovascular mortality and morbidity and type 2 diabetes [1-3]. MetS is characterized by central obesity, dyslipidemia, compromised fasting glucose, and hypertension [4]. However, the pathophysiologic mechanisms that lead to MetS are complex and not yet completely comprehended. MetS is a systemic problem with multiple organs affected and involved in the pathophysiology. Obesity is a main risk factor of MetS. Adipose tissue plays an important role on the genesis and progression of a number of clinical complications in other cells and tissues. New research approaches have revealed several types of biomolecules through which adipocytes communicate with distant cells and tissues. Adipose tissue crosstalk with other cell types and organs regulates energy homeostasis and function. Among these new discovered biomolecules, extracellular vesicles have triggered a lot of interest $[5,6]$. Extracellular vesicles are small membrane-bound vesicles $(100 \mathrm{~nm}-1 \mu \mathrm{m})$ secreted by cells into the extracellular space. The majority of EVs are considered exosomes for endosome-derived and microvesicles for plasma membrane-derived vesicles. EVs promote cell-cell crosstalk because they transport diverse bioactive molecules (lipids, proteins, small peptides, RNA and miRNA among others) [7]. It has been established that EVs interact with specific targets. Once released, EVs can interact with a target cell, deliver its cargo to the cytosol of the recipient cell, and modulate its phenotype. EVs such as exosomes can transfer functional protein and translatable mRNA, miRNA or siRNAs cargo that could activate or silence recipient target genes $[8,9]$. The mechanisms for EVs uptake is still matter of debate, however, an active uptake process with specialized intracellular transport machinery has been proposed [10]. EVs play an important physiological role on the integral communication between cells, tissues and distant organs. Therefore, is only logic to consider that these subcellular particles can also be involved in pathophysiological mechanisms in diseases. The role of EVs on MetS have recently been reviewed [5]. The emphasis has been to highlight the EVs as biomarkers in humans but also as determinants of metabolic diseases including MetS and potential therapeutic targets. Diabetes and MetS have been considered inflammatory diseases and macrophages play a key role in the pathophysiology. Macrophages-derived exosomes from adipose tissue are postulated to disseminate the disease to other tissues. However, macrophages seem to communicate with other cells in more sophisticated ways. Local macrophages exist in all tissues. It has been reported recently that macrophages located in the heart facilitate electrical conduction interacting via $\mathrm{Cx} 43$-containing gap junctions [11]. The mechanisms or mediators of this interaction are to be discovered. However, these results stress the complexity of cell-cell crosstalk. Macrophages are susceptible to metabolic changes and signaling from other tissues such as adipose tissue. The questions are: how local macrophages in specific organs are affected by signaling from macrophages from adipose tissue? And how dysfunctional signaling, in MetS for instance, can affect these local macrophages that in turn impair function? Answers to these questions will provide knowledge to identify new therapeutic targets for metabolic diseases.

\section{Funding}

This Manuscript was supported by Grant from UC-MEXUS CONACYT (CN 15-1489).

\section{References}

1. Dekker JM, Girman C, Rhodes T, Nijpels G, Stehouwer CD, et al. (2005) Metabolic syndrome and 10-year cardiovascular disease risk in the Hoorn Study. Circulation 112: 666-673.

2. Galassi A, Reynolds K, He J (2006) Metabolic syndrome and risk of cardiovascular disease: a meta-analysis. Am J Med 119: 812-819.

3. Isomaa B, Almgren P, Tuomi T, Forsén B, Lahti K, et al. (2001) Cardiovascular morbidity and mortality associated with the metabolic syndrome. Diabetes Care 24: 683-689.

4. Tziomalos K, Athyros VG, Karagiannis A, Mikhailidis DP (2010) Endothelial dysfunction in metabolic syndrome: Prevalence, pathogenesis and management. Nutr Metab Cardiovasc Dis 20: 140-146.

5. Martínez MC, Andriantsitohaina R (2017) Extracellular Vesicles in Metabolic Syndrome. Circ Res 120: 1674-1686.

6. Choi CHJ, Cohen P (2017) Adipose crosstalk with other cell types in health and disease. Exp Cell Res .

7. Raposo G, Stoorvogel W (2013) Extracellular vesicles: exosomes, microvesicles, and friends. J Cell Biol 200: 373-383.

8. Montecalvo A, Larregina AT, Shufesky WJ, Beer Stolz D, Sullivan MLG, et al. (2012) Mechanism of transfer of functional microRNAs between mouse dendritic cells via exosomes. Blood 119: 756-766.

9. Alvarez-Erviti L, Seow Y, Yin H, Betts C, Lakhal S, et al. (2011) Delivery of siRNA to the mouse brain by systemic injection of targeted exosomes. Nat Biotechnol 29: 341-345.

10. Mulcahy LA, Pink RC, Carter DR (2014) Routes and mechanisms of extracellular vesicle uptake. J Extracell Vesicles 3.

11. Hulsmans M, Clauss S, Xiao L, Aguirre AD, King KR, et al. (2017) Macrophages Facilitate Electrical Conduction in the Heart. Cell 169: 510-522. 